\title{
Ameloblastic fibro-odontoma located in the maxilla of a 3-year-old girl
}

Ülgür, Ismail I ; Caduff, Rosmarie ; Erb, Juliane ; van Waes, Hubertus ; Jacobsen, Christine ; Bredell, Marius G

DOI: https://doi.org/10.1016/j.pdj.2013.12.004

Posted at the Zurich Open Repository and Archive, University of Zurich ZORA URL: https://doi.org/10.5167/uzh-104897

Journal Article

Originally published at:

Ülgür, Ismail I; Caduff, Rosmarie; Erb, Juliane; van Waes, Hubertus; Jacobsen, Christine; Bredell, Marius G (2014). Ameloblastic fibro-odontoma located in the maxilla of a 3-year-old girl. Pediatric Dental Journal, 24(2):106-110.

DOI: https://doi.org/10.1016/j.pdj.2013.12.004 


\section{AUTHOR QUERY FORM}

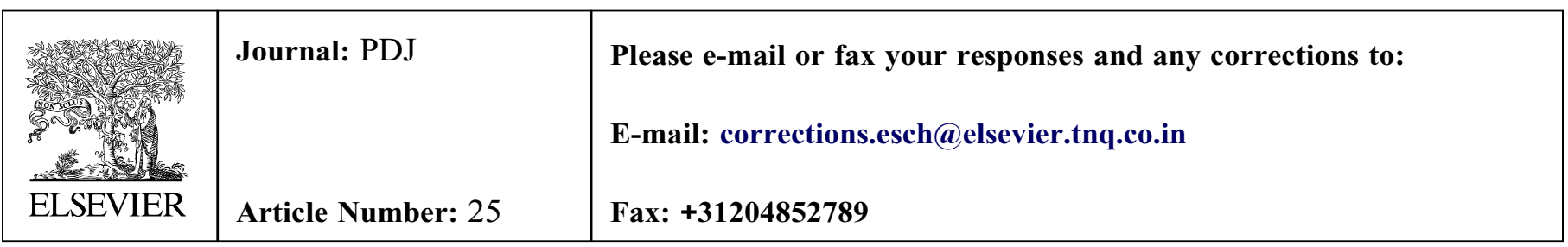

Dear Author,

Please check your proof carefully and mark all corrections at the appropriate place in the proof (e.g., by using on-screen annotation in the PDF file) or compile them in a separate list. Note: if you opt to annotate the file with software other than Adobe Reader then please also highlight the appropriate place in the PDF file. To ensure fast publication of your paper please return your corrections within 48 hours.

For correction or revision of any artwork, please consult http://www.elsevier.com/artworkinstructions.

Any queries or remarks that have arisen during the processing of your manuscript are listed below and highlighted by flags in the proof.

\begin{tabular}{|c|l|}
\hline $\begin{array}{c}\text { Location } \\
\text { in article }\end{array}$ & \multicolumn{1}{c|}{$\begin{array}{c}\text { Query / Remark: Click on the Q link to find the query's location in text } \\
\text { Please insert your reply or correction at the corresponding line in the proof }\end{array}$} \\
\hline $\mathbf{Q 1}$ & $\begin{array}{l}\text { Please provide a structured abstract, eg: Aim, Methods, Results etc. as it is a journal requirement. } \\
\text { P2 }\end{array}$ \\
$\begin{array}{l}\text { Please confirm that given names and surnames have been identified correctly. } \\
\text { Please check this box or indicate } \\
\text { yourections to make to the PDF file }\end{array}$ \\
\hline
\end{tabular}

Thank you for your assistance. 


\title{
Case Report
}

\section{Ameloblastic fibro-odontoma located in the maxilla of a 3-year-old girl}

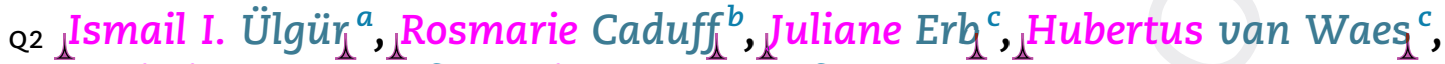 \\ ${ }_{\perp}$ Christine Jacobsen ${ }_{\perp}^{a}, \perp^{\text {Marius G. Bredell }}{ }^{a, *}$ \\ ${ }^{a}$ Department of Cranio-Maxillofacial and Oral Surgery, University Hospital of Zurich, Zurich, Switzerland \\ ${ }^{b}$ Institute of Surgical Pathology, University Hospital of Zurich, Zurich, Switzerland \\ ${ }^{\mathrm{c}}$ Department of Orthodontics and Pediatric Dentistry, Centre of Dental Medicine, University of Zurich, Zurich, \\ Switzerland
}

Q1

\section{Article history:}

Received 18 July 2013

Received in revised form

7 December 2013

Accepted 23 December 2013

Keywords:

Ameloblastic fibro-odontoma

Maxilla

Odontogenic tumor

Delayed eruption

\begin{abstract}
A B S T R A C T
Ameloblastic fibro-odontoma (AFO) is a rare benign tumor which contributes to ${ }_{1} 3 \%$ of all odontogenic tumors. AFO is mainly localized in the posterior region of the mandible and typical patients are children who present to their dentists due to non-erupting teeth. We describe an unusual example of a large AFO located in the upper right maxilla and maxillary sinus of a 3-year-old girl. The aims of this case report are to strengthen the knowledge of and to stimulate the discussion about AFO and to point out, that a conservative surgical procedure with regular follow up is highly recommended.
\end{abstract}

Copyright @ 2014 The Japanese Society of Pediatric Dentistry. Published by Elsevier Ltd. All rights reserved.

\section{Introduction}

Contributing to only $1_{\mathfrak{Z}} 3 \%$ of all odontogenic, tumors [1-4] the ameloblastic fibro-odontoma (AFO) was first described by Hooker in 1967 and distinguished from the more aggressive ameloblastic odontoma (AO), also called odontoameloblastoma [5]. According to the revised World Health Organization (WHO) Classification of odontogenic tumors of 2005, the AFO is described as a rare mixed odontogenic tumor which is usually benign [6]. The AFO shares similarities with the ameloblastic fibroma (AF) and the ameloblastic fibrodentinoma (AFD) but may be distinguished from these two entities by the presence of dentin and enamel on histological examination [6-8].

A current study describes a mean age of 9.6 years which underlines the fact that AFOs are predominantly found in children, and comprise around $7 \%$ of all odontogenic tumors under the age of $16[3,9]$. Commonly, these lesions are found on routine radiography of patients with delayed eruption of teeth or in patients presenting with asymptomatic intraoral swellings [10].

Radiographs generally show well-defined radiolucent areas containing various amounts of radio opaque material of irregular size and form with the radiopaque areas dominating in most cases [4,5,10-12]. Earlier tumors may initially present

* Corresponding author. Department of Cranio-Maxillofacial and Oral Surgery of the University Hospital of Zurich, Frauenklinikstrasse 24, 8091 Zürich, Switzerland. Tel.: +41 (0)44 2559056; fax: +41 (0)44 2554179.

E-mail address: Marius.Bredell@usz.ch (M.G. Bredell). http://dx.doi.org/10.1016/j.pdj.2013.12.004

0917-2394/Copyright @ 2014 The Japanese Society of Pediatric Dentistry. Published by Elsevier Ltd. All rights reserved. 
as radiolucent areas only and could show calcification in later stages of development [13].

Even though there seems to be a clear definition after the WHO Classification of 2005 concerning AF, AFD and AFO, there are still many controversies regarding the etiology, histology, therapy and prospective outlook $[4,14]$. Our case report aims to further the discussion and classification of such tumors by presenting a patient with a large ameloblastic fibro-odontoma involving an unusual location, namely the maxillary sinus.

\section{Case report}

A three-year-old girl was referred to the Department of Pediatric Dentistry at the University of Zurich by her private dentist after the mother noted a swelling in the upper right maxilla and non-eruption of a tooth in the related area. Noneruption of the first deciduous molar as well as a hard, tumorous entity in the described region was clinically seen by her private dentist and a large opacity was seen on the dental radiograph (Fig. 1). The dentist was concerned for an infection of the sinus cavity and referred the patient to the Pediatric Dentistry Department, University of Zurich.

The child was a healthy, well-nourished girl with an unremarkable social, medical and family history. Additionally there were no related histories or clinical signs of trauma or infection in the described area and oral inspection showed adequate oral hygiene.

Clinically there was a slight swelling in the region of teeth 54 and 55, with tooth 54 being absent. Palpatory examination however revealed a non-tender, bony hard high buccal swelling in the region of the right maxilla. The orthopantomograph revealed an erupted tooth 55 but instead of tooth 54 a complex of predominant opacities and more peripheral radiolucent areas could be detected. The lesion extended into the maxillary sinus with conforming tooth displacement (Fig. 2).

The differential diagnosis from the pediatric dentist included an odontoma and therefore the patient was sent to the Department of Cranio-maxillofacial and Oral Surgery of the University Hospital of Zurich for further examination.

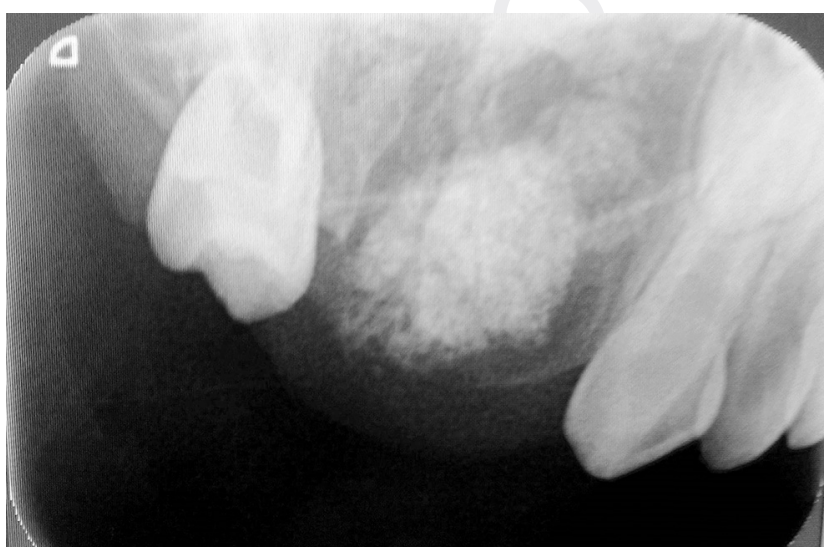

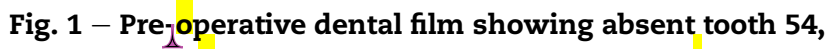
central radio ${ }_{1}$ opaque area surrounded by a radiglucent area.

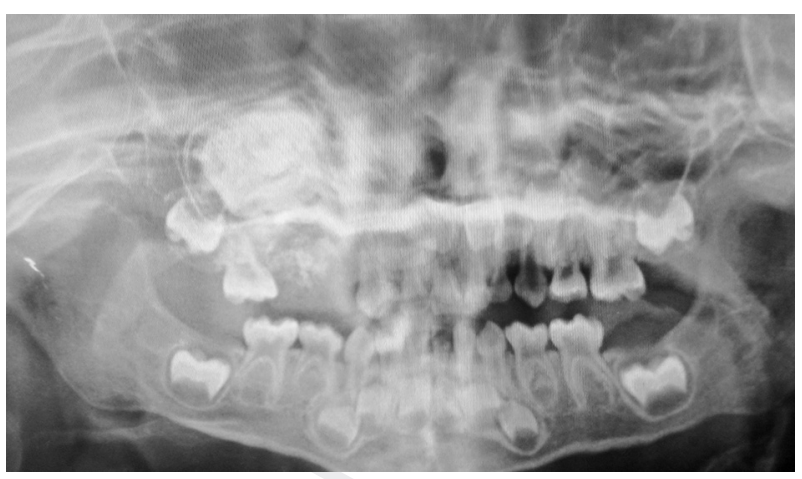

Fig. 2 - Orthopantomogram view showing the comparative obliteration of the right maxillary sinus.

Volume tomography (Fig. 3a, b and c) revealed a large calcifying tumor of the upper right maxilla involving the 54/55 area, reaching into the upper right maxillary sinus and filling out the latter nearly completely with conforming tooth displacement. A biopsy was performed under general anesthesia including bony-like fragments and firm white ${ }_{1} g r a y$ tissue- fragments measuring $18 \times 18 \times 9 \mathrm{~mm}$.

Histopathological examination revealed a composite tumor of well-formed dentin and enamel lying in a cell rich myxoid stroma without mitotic activity consistent with the diagnosis of an ameloblastic fibro-odontoma (Fig. 4a, b).

The tumor was resected two months later under general anesthesia at the Children's Hospital of Zurich. Access to the tumor was obtained via an extended lateral buccal vestibular incision. Wide, sub periosteal exposure of the lateral and anterior wall of the maxillary sinus was achieved and the inferior orbital nerve was isolated and protected. The lateral wall of the maxillary sinus was removed and the tumor was identified from the maxillary alveolus up to the cranial extension thereof. Due to its large size, the tumor had to be segmented with a bur and chisel and then removed. Due to the clinical and radiological examination it can be presumed that the permanent tooth follicles were involved in the pathological process and partial anodontia will result in this area. The defect was not filled with any material and direct closure was achieved with resorbable sutures, avoiding the risk of an oroantral communication.

The postoperative histological examination was identical to the biopsy done before and confirmed the diagnosis of AFO. Immediate and late post-operative healing was uneventful. Two months after the tumor ablation an additional low radiation dose volume tomogram was done, confirming complete removal of the tumor (Fig. 5a, b). In a follow up control by means of a low resolution volume tomogram six months later no recurrence was noted.

\section{Discussion}

This case study shows an unusual large and less common location of an AFO occurring in a three-year-old girl. In the literature only few studies are dealing with ameloblastic fibroodontoma involving the maxillary sinus $[13,15,16]$. Buchner [9] 


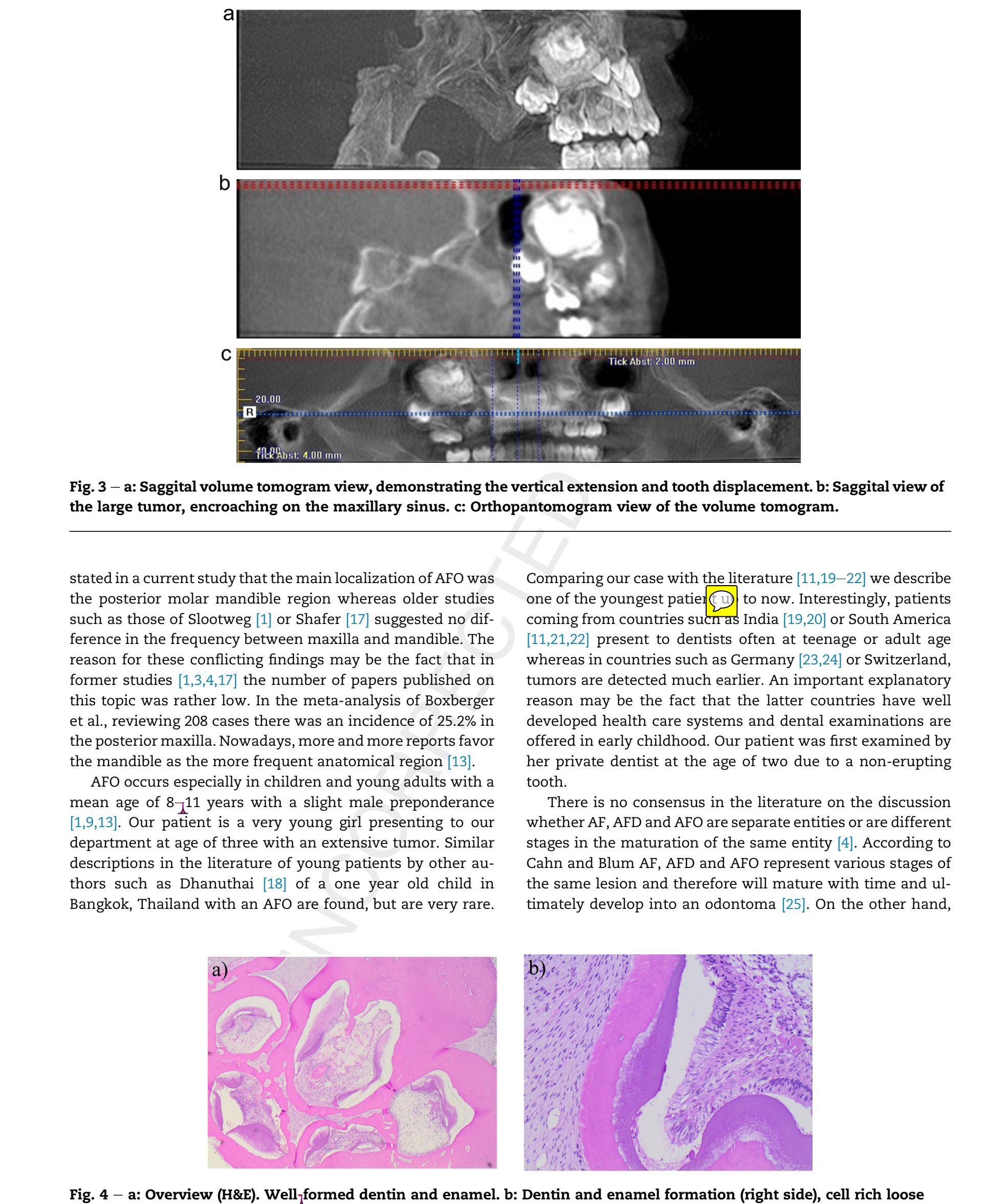

b
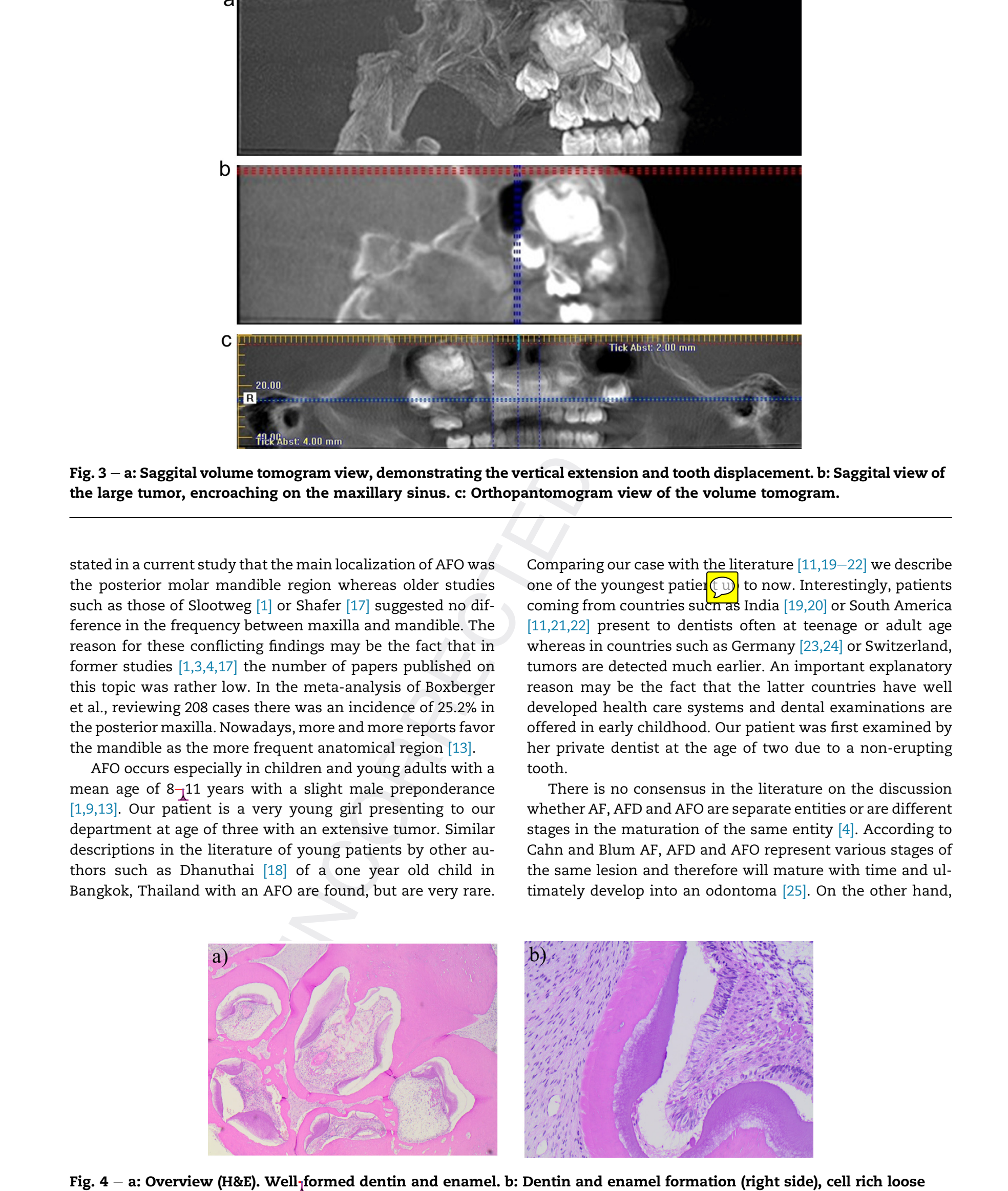

Fig. 3 - a: Saggital volume tomogram view, demonstrating the vertical extension and tooth displacement. b: Saggital view of the large tumor, encroaching on the maxillary sinus. c: Orthopantomogram view of the volume tomogram. stated in a current study that the main localization of AFO was the posterior molar mandible region whereas older studies such as those of Slootweg [1] or Shafer [17] suggested no difference in the frequency between maxilla and mandible. The reason for these conflicting findings may be the fact that in former studies $[1,3,4,17]$ the number of papers published on this topic was rather low. In the meta-analysis of Boxberger et al., reviewing 208 cases there was an incidence of $25.2 \%$ in the posterior maxilla. Nowadays, more and more reports favor the mandible as the more frequent anatomical region [13].

AFO occurs especially in children and young adults with a mean age of $8-11$ years with a slight male preponderance $[1,9,13]$. Our patient is a very young girl presenting to our department at age of three with an extensive tumor. Similar descriptions in the literature of young patients by other authors such as Dhanuthai [18] of a one year old child in Bangkok, Thailand with an AFO are found, but are very rare.
Comparing our case with the literature [11,19-22] we describe one of the youngest patien to now. Interestingly, patients coming from countries sucn as India $[19,20]$ or South America $[11,21,22]$ present to dentists often at teenage or adult age whereas in countries such as Germany $[23,24]$ or Switzerland, tumors are detected much earlier. An important explanatory reason may be the fact that the latter countries have well developed health care systems and dental examinations are offered in early childhood. Our patient was first examined by her private dentist at the age of two due to a non-erupting tooth.

There is no consensus in the literature on the discussion whether AF, AFD and AFO are separate entities or are different stages in the maturation of the same entity [4]. According to Cahn and Blum AF, AFD and AFO represent various stages of the same lesion and therefore will mature with time and ultimately develop into an odontoma [25]. On the other hand,
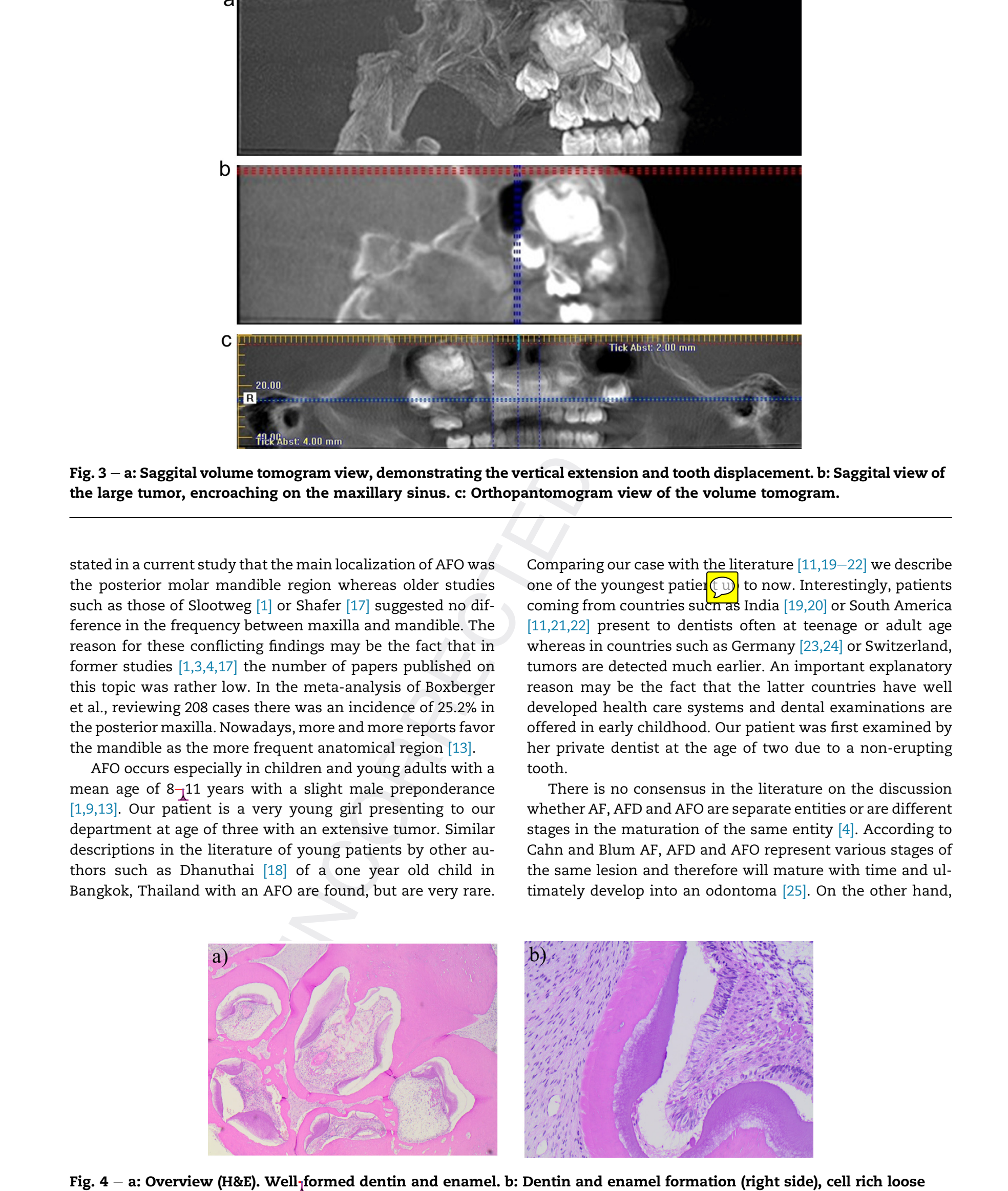

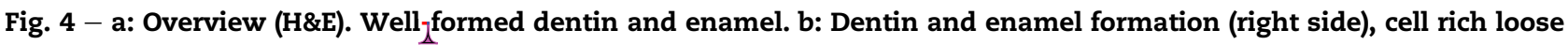
stroma (left side) (H\&E). 

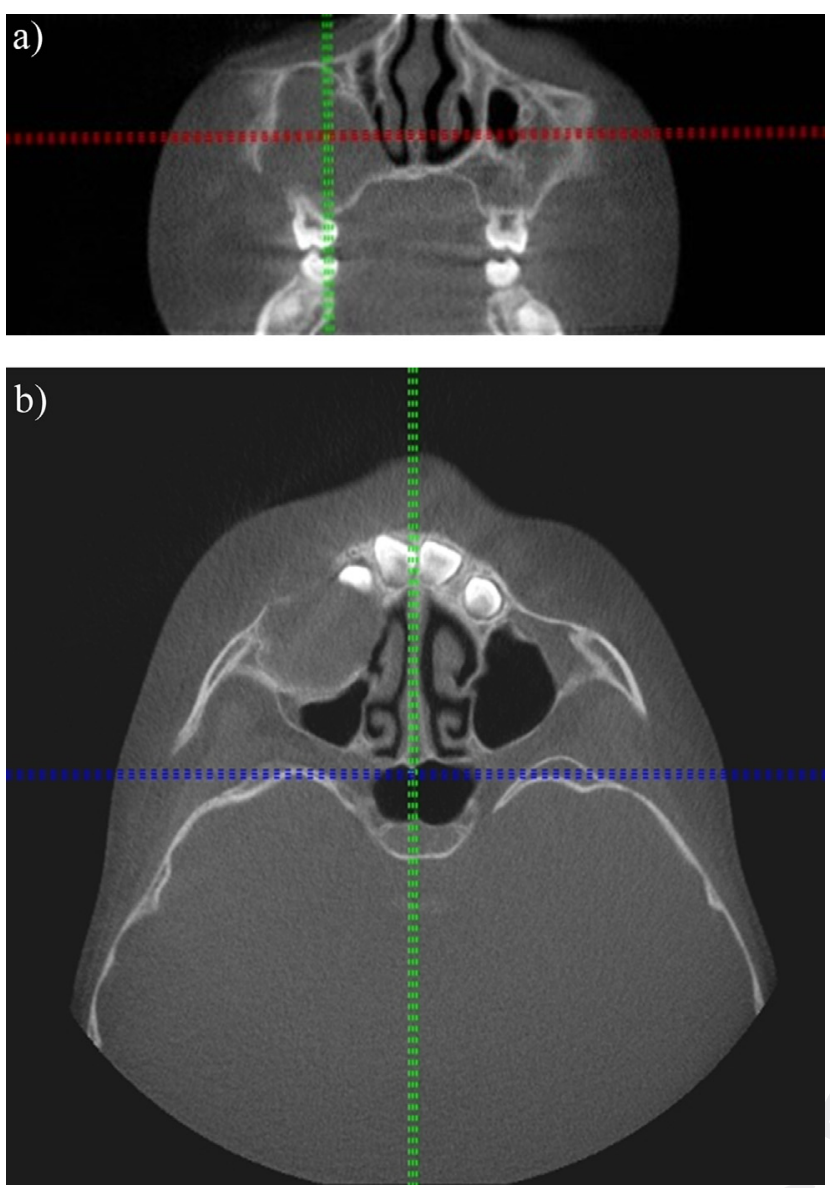

Fig. 5 - a and b: Post $t_{2}$ operative coronal and axial views demonstrating complete removal of the tumor.

many studies available support the classification of the WHO 2005 presenting the AFO as a separate entity without progression to an odontoma [6].

This view is supported by a review study [26] which demonstrates that $92.7 \%$ of all reported recurrent AFs showed no evidence of maturation into a more differentiated odontogenic lesion such as AFO. In general, a tendency towards acceptation of the WHO histological classification can be observed, as in the case of our case presentation as well. In accordance with the WHO classification our diagnosis of AFO was supported by the existence of enamel and dentin in the histopathological examination.

This case study supports the attitude of conservative and non-aggressive approach as described in the literature because AFO are non ${ }_{\lambda}$ malignant lesions and the probability of recurrence can be described as low. As reported above a small part of the maxillary sinus was exposed and partially involved in the surgical resection. A more aggressive treatment as described by Girradi concerning fibrodentinoma [20] is not recommended because of increased morbidity. Especially in the mandible, the risk of a pathological fracture is very high when performing a marginal resection and thus cannot be supported when compared to a more conservative procedure of tumor tissue removal [14]. At this age involvement of primary teeth is the rule rather than an exception. Displacement or even absence of permanent teeth as in this case may occur and needs careful follow up.

Friedrich [27] described a malignant and aggressive transformation 18 months after treatment and Furst [28] presented a case with a recurrence two years after surgery. An average recurrence rate of $7.4 \%$ is reported [13]. Howell and Burks demonstrated 2 cases of ameloblastic fibro-odontoma transforming to ameloblastic fibrosarcoma [29].

Even though the occurrence of malignant transformation is rare [29] a strict follow up is recommended. An example of such a diligent control is mentioned in the study of Scheuer [23] where a patient was operated at age of 3.5 years and then followed up for more than 21.5 years without recurrence, however a 2 year follow up may suffice [13]. Follow up should be clinical and complimented with a radiological examination that would demonstrate the tumor adequately. Low resolution volume tomography at six months post operatively and then yearly for two years may be helpful in this regard and limit cumulative radiation in children.

\section{Conclusion}

In conclusion, the authors would like to contribute this unusual case of a young girl to further the knowledge regarding this odontogenic tumor, to recommend a conservative surgical management and a regular follow- up protocol for at least two years to rule out any evidence of recurrence or the rare malignant transformation [11,19,27].

\section{Disclosure}

None of the authors have any conflicts of interest that should be disclosed.

\section{Conflict of interest statement}

The authors state that there are no any financial, personal or organizational relationships that could inappropriately influence this publication.

\section{R E F E R E N C E S}

[1] Slootweg PJ. An analysis of the interrelationship of the mixed odontogenic tumors-ameloblastic fibroma, ameloblastic fibro-odontoma, and the odontomas. Oral Surg Oral Med Oral Pathol 1981;51:266-76.

[2] Daley TD, Lovas GL. Ameloblastic fibro-odontoma: report of a case. J Can Dent Assoc 1982;48:467-9.

[3] Philipsen HP, Reichart PA, Praetorius F. Mixed odontogenic tumours and odontomas. Considerations on interrelationship. Review of the literature and presentation of 134 new cases of odontomas. Oral Oncol 1997;33:86-99.

[4] De Riu G, Meloni SM, Contini M, et al. Ameloblastic fibroodontoma. Case report and review of the literature. J Craniomaxillofac Surg 2010;38:141-4.

[5] Hooker SP. Ameloblastic odontoma: an analysis of twentysix cases. Oral Surg Oral Med Oral Pathol 1967;24:375-6. 
[6] Barnes L, Eveson JW, Reichart P, et al. World Health Organization classification of tumours. Pathology and genetics of head and neck tumours. Lyon: IARC Press; 2005. pp. 294-5.

[7] Kramer IR, Pindborg JJ, Shear M. The World Health Organization histological typing of odontogenic tumours. Introducing the second edition. Eur J Cancer B Oral Oncol 1993;29B:169-71.

[8] Matsuzaka $\mathrm{K}$, Inoue $\mathrm{T}$, Nashimoto $\mathrm{M}$, et al. A case of an ameloblastic fibro-odontoma arising from a calcifying odontogenic cyst. Bull Tokyo Dent Coll 2001;42:51-5.

[9] Buchner A, Kaffe I, Vered M. Clinical and radiological profile of ameloblastic fibro-odontoma: an update on an uncommon odontogenic tumor based on a critical analysis of 114 cases. Head Neck Pathol 2013;7:54-63.

[10] Chang H, Precious DS, Shimizu MS. Ameloblastic fibroodontoma: a case report. J Can Dent Assoc 2002;68:243-6.

[11] de Souza Tolentino E, Centurion BS, Lima MC, et al. Ameloblastic fibro-odontoma: a diagnostic challenge. Int J Dent; 2010. http://dx.doi.org/10.1155/2010/104630. pii:104630 [Epub 2010 Aug 19].

[12] Phillips MD, Closmann JJ, Baus MR, et al. Hybrid odontogenic tumor with features of ameloblastic fibro-odontoma, calcifying odontogenic cyst, and adenomatoid odontogenic tumor: a case report and review of the literature. J Oral Maxillofac Surg 2010;68:470-4.

[13] Boxberger NR, Brannon RB, Fowler CB. Ameloblastic fibroodontoma: a clinicopathologic study of 12 cases. J Clin Pediatr Dent 2011;35:397-403.

[14] Reibel J, Grønbaek AB, Poulsen S. Peripheral ameloblastic fibro-odontoma or peripheral developing complex odontoma: report of a case. Int J Paediatr Dent 2011;21:468-70.

[15] Ozer E, Pabuccuoglu U, Gunbay U, et al. Ameloblastic fibroodontoma of the maxilla: case report. J Clin Pediatr Dent 1997;21:329-31.

[16] Dolanmaz D, Pampu AA, Kalayci A, et al. An unusual size of ameloblastic fibro-odontoma. Dentomaxillofac Radiol 2008;37:179-82.

[17] Shafer WG, Hine MK, Levy BM. A textbook of oral pathology. Philadelphia: W.B. Saunders; 1983. pp. 304-13.
[18] Dhanuthai K, Kongin K. Ameloblastic fibro-odontoma: a case report. J Clin Pediatr Dent 2004;29:75-7.

[19] Pillai A, Moghe S, Guru KN, et al. Large ameloblastic fibroodontoma in an 18-year-old girl and review of literature. BMJ Case Rep; Nov 19;2012. http://dx.doi.org/10.1136/bcr-2012007160. pii:bcr-2012-007160.

[20] Giraddi GB, Garg V. Aggressive atypical ameloblastic fibrodentinoma: report of a case. Contemp Clin Dent 2012;3:97-102.

[21] Pontes HA, Pontes FS, Lameira AG, et al. Report of four cases of ameloblastic fibro-odontoma in mandible and discussion of the literature about the treatment. J Craniomaxillofac Surg 2012;40:e59-63.

[22] Reis SR, de Freitas CE, do Espirito Santo AR. Management of ameloblastic fibro-odontoma in a 6-year-old girl preserving the associated impacted permanent tooth. J Oral Sci 2007;49:331-5.

[23] Scheuer HA, Höltje WJ. Interdisciplinary treatment of a $31 /$ 2-year-old child with extensive ameloblastic fibroodontoma. Case report and follow-up documentation over 21 1/2 years [in German] Mund Kiefer Gesichtschir 2001;5:367-71.

[24] Oghli AA, Scuto I, Ziegler C, et al. A large ameloblastic fibroodontoma of the right mandible. Med Oral Patol Oral Cir Bucal 2007;12:E34-7.

[25] Cahn LR, Blum T. Ameloblastic odontoma: case report critically analyzed (letter). J Oral Surg 1952;10:169-70.

[26] Chen Y, Wang JM, Li TJ. Ameloblastic fibroma: a review of published studies with special reference to its nature and biological behavior. Oral Oncol 2007;43:960-9.

[27] Friedrich RE, Siegert J, Karl Donath, et al. Recurrent ameloblastic fibro-odontoma in a 10-year-old boy. J Oral Maxillofac Surg 2001;59:1362-6.

[28] Furst I, Pharoah M, Phillips J. Recurrence of an ameloblastic fibro-odontoma in a 9-year-old boy. J Oral Maxillofac Surg 1999;57:620-3.

[29] Howell RM, Burkes Jr EJ. Malignant transformation of ameloblastic fibro-odontoma to ameloblastic fibrosarcoma. Oral Surg Oral Med Oral Pathol 1977;43:391-401. 